\title{
doispontos:
}

\section{Um remédio para os males da sensibilidade: a psicologia empírica de Sulzer}

\author{
A Remedy for the distresses of sensibility: Sulzer's empirical psychology \\ Oliver Tolle \\ Professor do Departamento de Filosofia da Universidade de São Paulo - USP \\ oliver.tolle@gmail.com
}

Resumo: A natureza ilusória da sensibilidade, desde sempre evidente pelas dificuldades presentes na obtenção de conhecimento verdadeiro de si mesmo e do mundo, encontra em Sulzer um remédio que surpreende por sua estratégia inaudita. Em vez de recomendar o controle das sensações e paixões por meio das faculdades superiores, quer dizer, do entendimento e da razão - o que se tornou, por assim dizer, uma máxima filosófica - Sulzer defende que a ilusão só pode ser dissipada por um retorno constante à sensibilidade, até que ela aprenda a lidar consistentemente com os seus conteúdos.

Palavras-chave: Física da alma; psicologia empírica; sensibilidade; dualismo.

Abstract: The illusory nature of sensibility, always evident in the difficulties present in obtaining true knowledge of oneself and the world, finds in Sulzer a remedy that surprises for its unprecedented strategy. Instead of recommending the control of sensations and passions through higher faculties, that is, understanding and reason - which has become a philosophical maxim - , Sulzer argues that illusion can only be dispelled by a constant return to sensitivity, until it learns to consistently handle its contents.

Keywords: Physics of the soul; empirical psychology; sensitivity; dualism. 
Desde o início de sua obra, preocupado com as possibilidades práticas da psicologia, Sulzer adverte que o conhecimento empírico é de tal modo, que não somos capazes de obter um conhecimento absolutamente claro dele. Em parte, isso se deve à natureza essencialmente complexa das sensações. Por mais que nos esforcemos, podemos nos deter apenas em uma parcela ínfima daquilo que se apresenta aos nossos sentidos. E mesmo que tenhamos clareza sobre um determinado aspecto, ele depende da situação à que se encontra relacionado e do que esperamos dele. Por isso somos tão facilmente enganados pelos sentidos. Nos sonhos, por exemplo, somos colocados diante de percepções claras, que acabam fazendo com que tomemos algo ilusório por real e efetivo. Leibniz já tinha observado que a apercepção ${ }^{1}$ não é capaz de reconhecer a diferença entre o mundo onírico e o mundo real, a não ser que se apresente uma descontinuidade no primeiro - se ela não se apresenta, a consciência permanece convicta de que o que tem diante de si é real e age consequentemente, tal como no mundo efetivo. Mas se o sonho possui a vantagem de que em algum momento o indivíduo desperta dele, rompendo assim a ilusão, o mesmo não ocorre com ilusões de que a consciência desperta é suscetível. Um exemplo extremo de uma ilusão desse tipo é o de um fanático religioso que julga ter visto um anjo. Não é difícil conceber situações em que esse equívoco pode ter lugar. A introdução repentina de um ator fantasiado numa situação de suscetibilidade emocional é capaz de confundir até os espíritos mais atentos. Ocorre assim que a sensibilidade é um ponto de apoio muito frágil para chegar a conhecimentos bem estabelecidos. Infelizmente, a alma humana não tem como se furtar a essa fragilidade.

Por mais metódica que seja a investigação do sensível, ela precisa lidar com o fato de que boa parte daquilo que ela conhece é o resultado de coisas que ela não percebe atualmente ou simplesmente não é capaz de perceber. Um indivíduo doente, por exemplo, toma consciência dos efeitos perceptíveis de sua doença, mas não lhe é dada a oportunidade de identificar, pura e simplesmente pelos seus sentidos, toda a complexidade de acontecimentos e agentes que conduziram a ela ou mesmo o que deve esperar dali por diante. É claro que um médico experimentado ou dotado de um microscópio pode orientá-lo, mas isso não resolve ad aeternum a dificuldade. O problema é que somos chamados o tempo todo a situações cuja natureza obscura só pode ser ignorada pelo hábito e procedimentos mecânicos, que apenas iludem a consciência de que ela possui um conhecimento claro graças a conjecturas de semelhança e diferença. E o preço que esse comportamento exige é muito caro: nada menos do que o enfraquecimento da nossa capacidade investigativa. Na verdade, a nossa própria racionalidade fica prejudicada, porque ela passa a adotar uma postura de convicção que está longe de se sustentar com base naquilo de que ela efetivamente dispõe.

Como é apenas muito provável que haja muitas coisas no mundo material para os quais não possuímos sentidos, e que percebemos mesmo os objetos que se relacionam com os nossos sentidos apenas de modo muito imperfeito, então não é de se admirar que, por um lado, não sabemos quase nada sobre as coisas no mundo e que, por outro lado, o homem mais sensato está sempre submetido a equívocos e ilusões. Há apenas diferença nos equívocos do tolo e nos equívocos do filósofo esclarecido, que aquele erra em questões que pertencem à vida comum e este em suas especulações sobre a física do mundo material (SULZER, 2011, p. 37).

Como evitar então essa fragilidade do conhecimento empírico? Ao contrário da formação de hábitos aparentemente seguros, Sulzer recomenda uma outra via, muito mais difícil, mas que responde em grande medida aos apelos de um desenvolvimento constante do espírito contidos na alternativa filosófica leibniziana e, ao mesmo tempo, pode evitar o conforto da ilusão, que normalmente resulta em distúrbios cognitivos. Assim, em vez de seguir pelo costume ou pelo uso unilateral da razão, a consciência deve se dirigir reiteradamente para o mundo sensível. Diz Sulzer:

Apenas mediante percepções sensíveis constantes e diversificadas no que diz respeito à efetividade da nossa condição exterior podemos conservar a saúde de nossa razão. Podemos julgar e concluir corretamente sobre coisas ideais, passar de uma conclusão à outra e realizá-lo precisamente segundo as regras da lógica e, não obstante, no

\footnotetext{
${ }^{1}$ Como observa Udo Thiel, Sulzer utiliza o termo "apperception" na redação francesa de alguns de seus artigos, mas quando os traduz para o alemão emprega "Bewusstsein” [consciência]. Thiel, U. Sulzer über Bewusstsein im Kontext; In: GRUNERT, 2011, p. 23.
} 
que diz respeito às coisas efetivas e à nossa condição no mundo, pensar de modo completamente equivocado (SULZER, 1782, p. 223).

De certa maneira, o mundo empírico já exige de nós naturalmente esse procedimento. Graças ao choque entre nossas expectativas e juízos e nossas experiências, somos o tempo todo obrigados a voltar a nossa atenção para as percepções e examinar novamente o que ocorre ao nosso redor. Mas é possível ir além disso e preparar adequadamente as nossas faculdades para esse enfrentamento constante com o mundo efetivo. Para Sulzer, a conjunção de quatro aspectos favorece a disposição adequada da consciência diante da confusão que reina em seu aparelho sensório: atenção expandida, saúde dos órgãos sensíveis (quer dizer, do corpo como um todo), imaginação ativa e memória. Particularmente importante aqui é a valorização da memória, pois Sulzer recupera um elemento central da psicologia empírica de Baumgarten, a saber, que uma percepção qualquer é a somatória do conteúdo da percepção atual com as percepções passadas guardadas na memória. Pode servir de auxílio aqui um exemplo bastante ordinário: para Baumgarten, quando vemos uma xícara sobre a mesa, o conhecimento produzido por essa percepção não se reduz apenas aos dados sensoriais da visão atual, mas é completado por tudo aquilo que sabemos sobre xícaras e coisas semelhantes a partir de experiências anteriores. Assim, mesmo sem tocar a xícara, sei que ela é capaz de conter líquido no seu interior, que muito provavelmente a parte traseira, não vista, forma um todo circular uniforme com a parte dianteira, que ela tem certo peso, etc. ${ }^{2}$. Ao chamar a atenção para a memória, Sulzer, ao contrário do que pode parecer, não chama a atenção para a importância do hábito, que resulta justamente do acúmulo de experiências parecidas, mas sim para a necessidade constante de revisão do conteúdo armazenado, de modo a evitar equívocos. De modo resumido, Sulzer explica a sua solução da seguinte maneira:

\begin{abstract}
A matéria merece ser investigada a fundo, tanto quanto permitir o nosso conhecimento físico [... ]. Quero apenas acrescentar ainda uma única observação. As representações confusas, quando se encontram muito próximas umas das outras, resistem na maioria das vezes a esse estado de presença do espírito; elas são sereias, mas sereias tanto mais terríveis porque se percebe os efeitos de seus encantamentos sem vê-las ou ouvi-las. Contudo, essas representações tão prejudiciais para o discernimento e para a força da alma são no mais das vezes o efeito de uma representação chamativa que deixamos que nos atinja subitamente, assemelhando-se àquelas que despertam alegria, medo ou uma outra paixão qualquer. Se, por conseguinte, nos exercitássemos a ter uma boa conduta diante das primeiras impressões que visam despertar essas impressões prejudiciais, então com isso afastaríamos de nós o perigo de ver apenas um único lado de sua situação atual e conservaríamos a liberdade de expandir a nossa atenção tanto quanto permitissem as percepções sensíveis e a recordação do passado; e isso produziria uma presença do espírito que tornaria a consciência tão completa quanto consentem os limites previamente impostos às nossas forças (SULZER, 1782, p. 226).
\end{abstract}

A partir de uma caracterização mais detida dos processos psicológicos que acompanham a reflexão, Sulzer é capaz de extrair algumas conclusões inusitadas. Para ele, o esforço de alcançar um conhecimento claro a respeito de uma ideia acaba por enfraquecer a sensibilidade como um todo. Essa situação resulta em um aniquilamento da própria personalidade daquele que pensa abstratamente:

Enquanto o entendimento estiver ocupado com representar-se a si mesmo um certo conceito com absoluta clareza, ao mesmo tempo são enfraquecidas todas as outras forças da alma; nesse momento a alma nem percebe, nem tem inclinações nem vontade; pode-se inclusive dizer que nesse momento ela nem mesmo sente a si mesma, que ela se encontra meramente dedicada ao seu objeto (SULZER, 1782, p. 230).

Ao contrário, quando a alma se volta inteiramente para o que ocorre na esfera dos sentidos, ela é obrigada a lembrar-se de si mesma, porque então não pode mais tratar daquilo que ocorre com ela como algo estranho e alheio. A sensibilidade exige da alma completa participação, do que decorre que nela não são tão importantes os objetos que a afetam, mas sim como ela se faz afetar por eles. Então resulta em equívoco patente considerar, pela sensibilidade, os objetos como coisas meramente exteriores, com uma existência própria independente:

${ }^{2}$ A esse respeito, ver TOLLE, 2016, pp. 75-80. 
A sensação é, portanto, uma ação da alma que não tem nada em comum com o objeto que ela produz ou motiva. O que disse Descartes, que a dor não se encontra na agulha que a causa, é válido para todos os objetos que despertam uma certa sensação na alma. Durante a reflexão, o entendimento se encontra ocupado com um objeto que ela considera fora de si; durante a percepção, a alma se encontra ocupada apenas consigo mesma. Sem essa condição, a percepção não pode ocorrer. Já observei que mesmo as impressões mais intensas não são notadas pela reflexão; isso demonstra que as sensações só ocorrem na situação de representações obscuras (SULZER, 1782, p. 231-2).

Disso resulta uma estranha interpretação das nossas motivações. Para Sulzer, as nossas escolhas e predileções não têm origem na reflexão. Na verdade, não há um prazer associado ao esclarecimento de uma ideia, por mais difícil e demorada que ela seja. As nossas motivações se encontram exclusivamente na esfera da sensibilidade, e suas causas naturalmente são em grande parte obscuras, porém ainda mais obscuras para o filósofo abstrato e para o tolo que não investiga o que acontece com ele. É difícil evitar certo embaraço, quando lemos Sulzer explicar que, na verdade, o prazer que julgamos possuir ao obter uma ideia clara, por exemplo, graças à resolução de um problema difícil de geometria, na verdade é o prazer de voltarmos a nós mesmos, já que no momento em que focamos o nosso entendimento nos cálculos e demonstramos, somos obrigados a renunciar à nossa individualidade orgânica e sensitiva.

\section{$* * *$}

Ao redigir o seu dicionário Teoria Geral das Belas Artes, publicado em 1771-74, Sulzer já pode se movimentar em um edifício conceitual que não tem mais as escoras da metafísica. Os problemas da relação corpo e alma e, particularmente, da legitimação do conhecimento sensível não voltam a ser evocados. Isso não significa, contudo, que os seus pressupostos não estejam presentes ao longo das centenas e centenas de verbetes. Isso fica particularmente evidente naqueles destinados às diferentes faculdades inferiores do conhecimento - que foram anteriormente definidas por Wolff, Gottsched e Baumgarten -, mas também em alguns verbetes que tratam de regiões fronteiriças entre a razão e a sensibilidade, como é o caso de "Universal” e "Unidade”. Apoiando-se em uma passagem da Arte Poética de Horácio: "difficile est propria (proprie) communia dicere" [difícil é falar do universal especificamente] (v. 128), Sulzer observa que: "O universal é por duas razões inestético: porque ele é exposto por conceitos deduzidos e, portanto, distantes da sensibilidade; e também porque muitas vezes é demasiado comum e, por conseguinte, não estimula suficientemente a força representativa" (SULZER, 1771, p. 44). Se, por um lado, a dificuldade diz respeito a objetos que se destinam à fruição dos sentidos, dentre os quais se destacam as obras de arte, que justamente fornecem conhecimentos sobre os meandros da sensibilidade, por outro lado, ela evidencia uma fragilidade da pretensão de constituir um conhecimento puramente racional, já que ele depende da sensibilidade e, portanto, das relações entre pensamento e linguagem.

A esse propósito, Sulzer redigiu um pequeno texto, intitulado Observações sobre a influência recíproca da razão sobre a linguagem, e da linguagem sobre a razão. Ali, ele mostra como temos mais facilidade de lidar com palavras sensíveis e concretas do que com palavras abstratas:

Temos muito mais facilidade de nos lembrar de ideias sensíveis do que de ideias abstratas. Se as palavras não dessem corpo às ideias, só nos recordaríamos das ideias de coisas sensíveis, bem distintas por si mesmas, como aquelas de uma árvore, de um animal e de outras coisas semelhantes; todas as outras ideias se apagariam da mente sem o recurso das palavras (SULZER, 2011, p. 39).

A abstração é, por conseguinte, um conteúdo com o qual temos uma dificuldade muito maior de lidar. Daí a necessidade de palavras ou símbolos para isolar conhecimentos racionais, sem os quais o desenvolvimento da razão seria impossível. Para Sulzer, "os sentidos são tocados apenas por coisas singulares: por isso, o universal não pode jamais ser exposto sensivelmente, a não ser quando é dito no particular." Certas figuras da retórica permitem essa expressão do universal no particular, como no caso das imagens, dos exemplos, dos símiles e da alegoria, mas também algumas comparações, como no seguinte caso: "então não havia mais nenhuma virtude sobre a terra”, onde transparece a regra de que, para evocar o universal, não basta 
recorrer a pensamentos ordinários, mas sim a pensamentos que, em virtude de sua importância, causem uma impressão forte.

Sem dúvida, a contraposição que opera aqui é novamente aquela entre razão e sensibilidade, mas já dotada da tensão irreconciliável que a caracteriza desde Baumgarten. O conhecimento sensível é incompatível com o racional, porque ele resulta de um plano de experiências muito peculiar. Ora, um dos principais atributos deste conhecimento é a imediatez com que se oferece à atenção, não permitindo, por assim dizer, reflexão no instante em que se oferece. Mas esse é apenas um modo de qualificá-lo. Um outro atributo característico do conhecimento sensível é que ele se apresenta com graus diferentes de intensidade. Em termos mais precisos: ele só ganha clareza quando atinge certo grau de intensidade. Ora, Baumgarten tinha advertido para o fato de que uma imaginação esmaecida, que não foi previamente exercitada pela atenção e pela experiência, não pode conferir aos poemas a intensidade que eles merecem. Nesse sentido, a ênfase na atividade racional e no uso de conceitos universais produz um desequilíbrio no arranjo das faculdades cognitivas, o que Sulzer explica no trecho indicado como falta de estímulo para a força representativa.

Isso não significa, contudo, que o universal não é um tema ou objeto do conhecimento sensível em geral ou da arte. Ao contrário, o universal aparece com frequência nas representações dos poetas e artistas, que se valem de um recurso retórico bastante específico, a despeito da riqueza de seu repertório ao longo da história. Os modos de dizer o universal no ou por meio do particular são possíveis graças à capacidade de produzir imagens. Por conseguinte, para dizer o universal não basta recorrer a pensamentos comuns. O pensamento em questão, em virtude da sua importância, deve causar uma impressão forte no leitor ou espectador, isto é, no sujeito percipiente.

Sem dúvida, Sulzer não ignora os perigos de uma sensibilidade aflorada. Como vimos, para ele, o conteúdo dos sentidos, graças à sua natureza confusa, pode nos confundir. As ilusões e os equívocos são, portanto, muito comuns. Nos sonhos, por exemplo, somos levados, a partir de percepções claras e intensas, a tomar algo por real e efetivo, quando não o é. Do mesmo modo, um homem sensível, cuja fé em Deus por diversos motivos se tornou fervorosa, graças ao seu aparelho sensorial - quer dizer, mais especificamente à imaginação - pode julgar ter tido um contato com o sobrenatural. Esses tipos de desordem não são incomuns e podem perturbar as faculdades superiores do conhecimento, que não têm à disposição nenhum outro recurso para lidar com o problema senão silenciar a intensidade de suas sensações e paixões por meio da imposição de um discurso abstrato. Mas Sulzer não vê na ênfase do entendimento um remédio para os perigos da sensibilidade. Está em jogo aqui aquele mesmo princípio que garante a identificação do sonho à diferença da realidade, e que vale também para qualquer produto da imaginação, pois só o exame repetido daquilo que se apresenta à alma e a sua confrontação com as experiências acumuladas pode manter a saúde e a lucidez do indivíduo. Chama a atenção, contudo, que Sulzer comece a falar em termos de saúde, vinculando a problemas epistemológicos que dizem respeito a um conhecimento verdadeiro do mundo uma diversidade de estados da alma, desde a loucura mais evidente até a melancolia e a hipocondria ${ }^{3}$. Embora a psicologia empírica de Wolff a Baumgarten tenha demonstrado preocupação com os efeitos negativos da sobrevalorização do entendimento dentre as demais faculdades cognitivas, Sulzer pensa os dois lados - razão e sensibilidade -- simultaneamente com um equilíbrio que não se verá mais posteriormente. Também a razão, quando ganha autonomia em relação à sensibilidade, acaba por prejudicar a lide com o mundo efetivo e ordinário:

Podemos julgar e concluir corretamente sobre coisas ideais, passar de uma conclusão para a outra e realizá-lo precisamente segundo as regras da lógica, e não obstante, no que diz respeito às coisas efetivas e à nossa condição no mundo, pensar de modo completamente equivocado.

${ }^{3}$ A essse respeito, verificar o artigo de Stefanie Buchenau: A física da alma de Sulzer entre a medicina e a filosofia. In: BUCHENAU, 2020, pp. 7-39. 
O trecho acima não deve, todavia, ser interpretado como uma crítica ao modelo cognitivo de Wolff, que em nenhum momento defendeu a supremacia da razão. Ao contrário, o modelo mostra que a razão está ancorada em um conhecimento sensível bem construído por meio de atenção e exercícios. Talvez seja mais adequado falar aqui de uma mudança nas questões. Em Sulzer desaparecem gradativamente as demais questões tradicionais da metafísica: ontologia, cosmologia, teologia natural. Nem mesmo os temas da psicologia racional recebem destaque. A psicologia empírica se torna o centro e ponto de partida da sua filosofia. 


\section{Referências bibliográficas:}

BUCHENAU, S. Entre filosofia e medicina: estudos de psicologia alemã. Tradução de A. A. Fernandes, M. Suzuki e O. Tolle. São Paulo: Clandestina, 2020.

GRUNERT, F. e STIENING, G. (ed.); Johann Georg Sulzer (1720-1779) - Aufklärung zwischen Christian Wolff und David Hume. München: Akademie Verlag, 2011.

SULZER, J. G. Vermischte philosophische Schriften. Leipzig: Weidmanns Erben und Reich, 1782. . Allgemeine Theorie der schönen Künste. Leipzig: 1771-74.

Observações sobre a influência recíproca da razão sobre a linguagem, e da linguagem sobre a razão. Tradução de Márcio Suzuki. Cadernos UFS Filosofia - Ano 8, Fasc. XIV, Vol. 10, julho-dezembro, 2011. TOLLE, O. O Nascimento da Estética no Século XVIII. São Paulo: Editora Clandestina, 2016. 